\title{
III plano nacional de políticas para as mulheres: a transversalidade de gênero e a educação
}

\author{
Fernanda de Magalhães Trindade* \\ Instituto Federal Farroupilha \\ Maria Simone Vione Schwengber** \\ Universidade Regional do Noroeste do Estado do Rio Grande do Sul
}

Resumo $O$ presente artigo tem como objetivo compreender como, do ponto de vista das ênfases, tensões e desafios, a proposição governamental da transversalidade de gênero tem sido apresentada pelo Capítulo 1 do III Plano Nacional de Políticas para as Mulheres (2013-2015). Para tanto, realizou-se uma análise cultural e documental. Os resultados indicam que a transversalidade das políticas de gênero tem sido proposta como um princípio orientador desse Plano. Apresenta-se, de modo particular no Capítulo 1, na forma de um construto teórico, pautada no conceito da autonomia econômica; e como um construto prático, com ações voltadas para a educação profissional de mulheres pobres. Eis a economização do social como proposta para operar com a transversalidade das políticas de gênero, desenvolver a autonomia econômica das mulheres e reduzir as desigualdades de gênero no Brasil.

PALAVRAS-CHAVE: Autonomia econômica; Educação; Tansversalidade de gênero. 


\section{III national plano of policies for women: gender mainstreaming and education}

Abstract This article aims to understand how, from the point of view of the emphases, tensions and challenges, the government proposition of gender mainstreaming has been presented by Chapter 1 of the III National Plan of Policies for Women (2013-2015). For that, there was a cultural and documental analysis. The results indicate that mainstreaming of gender policies has been proposed as a guiding principle of this Plan. It presents, in particular in Chapter 1, in the form of a theoretical construct, based on the concept of economic autonomy; and as a practical construct, with actions for the professional education of poor women. Here is the economization of the social as proposed to operate with mainstreaming of gender policies, develop the economic autonomy of women and reducing gender inequalities in Brazil.

KEYWORDS: Economic autonomy; Education; Gender mainstreaming.

\section{Introdução}

Este artigo desdobra-se de uma pesquisa de Doutorado em Educação nas Ciências e resulta de uma pesquisa em rede, financiada pelo CNPq, intitulada Políticas públicas de inclusão social e transversalidade de gênero: ênfases, tensões e desafios atuais, coordenada pela Profa. Dra. Dagmar Meyer e desenvolvida por seis universidades brasileiras (UFRGS, Unijuí, UFRB, Ulbra, UFES, UFPB) ${ }^{1}$. Neste processo, tomamos como objeto de análise o Capítulo 1 - Igualdade no mundo do trabalho e autonomia econômica - do III Plano Nacional de Políticas para as Mulheres (PNPM) (2013$2015)^{2}$, com o objetivo de compreender como, do ponto de vista das ênfases, tensões e desafios, a proposição governamental da transversalidade de gênero tem sido apresentada e proposta nesse Capítulo.

Compreendemos políticas públicas "[...] (em sentido lato) como linguagem, como artefato cultural e como tecnologia de poder, [...] que têm se tornado um instrumento central de organização das sociedades contemporâneas" (MEYER, 2012, p. 50-51). Dessa forma, o III PNPM apresenta-se como uma política de ações afirmativas de governo, com o objetivo de viabilizar os direitos sociais das mulheres, garantir uma melhor qualidade de vida e minimizar as desigualdades de gênero presentes na sociedade brasileira.

Para atingir o objetivo proposto, nesta pesquisa recorremos a dois tipos de análise: documental e cultural. A análise documental constitui um importante instrumento na pesquisa qualitativa, que consiste na organização e interpretação de documentos previamente selecionados, neste caso o III PNPM, mais especificamente o Capítulo 1. Segundo Cellard (2008), com a análise documental é possível extrair informações, bem como ampliar o entendimento sobre o objeto da pesquisa, cuja compreensão necessita de contextualização histórica e sociocultural. Além disso, o uso de 
documentos em pesquisa permite acrescentar a dimensão do tempo à compreensão do social.

Após a análise documental, utilizamos a análise cultural no exame do processo de produção de significados. Recorremos a esse tipo de análise para compreender a linguagem que produz a materialidade do Capítulo examinado, conforme a cultura na qual estamos inseridos/as e somos, ao mesmo tempo, produtores/as. Os Estudos Culturais caracterizam-se pelo caráter interdisciplinar que exploram as formas de produção de significados e sua difusão nas sociedades atuais. Esse processo de produção de significados mostra a regulação dos discursos e das ações presentes nas políticas públicas (MATTELART; NEVEU, 2004; JOHNSON et al., 2006).

Nesse contexto dos Estudos Culturais, o uso que fazemos do conceito de gênero nos afasta das abordagens que "colam" um determinado gênero a um sexo anatômico que lhe seria naturalmente correspondente, e que tendem a focalizar desigualdades e subordinações derivadas do desempenho de papéis, funções e características culturais próprias de mulheres e de homens, para aproximar-nos de abordagens que tematizam o social e a cultura, em sentido amplo, assumindo que esses são constituídos, atravessados e/ou organizados por discursos instituintes de feminilidades e de masculinidades que, ao mesmo tempo, os produzem e/ou ressignificam (NICHOLSON, 2000; LOURO, 2003; MEYER, 2003).

Assim, definido o que entendemos por gênero, implica considerar nas próximas seções o que o III PNPM entende por transversalidade de gênero, como ela é implementada e com que efeitos isso se tem dado, especialmente ao analisar o Capítulo 1. Na primeira seção após a introdução, localizamos as primeiras evidências do aparecimento da expressão transversalidade de gênero no Plano. Na segunda e na terceira, analisamos a transversalidade enquanto construto teórico e prático, e de que forma utiliza a educação para atingir a igualdade de gênero.

\section{A transversalidade de gênero no III PNPM: primeiras evi- dências}

Nesta seção, realizamos um movimento inicial de análise nas páginas introdutórias do III PNPM (2013-2015), que antecedem ao Capítulo 1, para identificar o que esse Plano entende por transversalidade de gênero. Percebemos que a transversalidade é proposta "como princípio orientador de todas as políticas públicas" e aparece associada à expressão transversalidade das políticas de gênero (BRASIL, 2013, p. 9-10).

A transversalidade, de acordo com Viotti (2006), pretende garantir que a perspectiva de gênero seja incorporada por todas as esferas das políticas públicas de um governo, e é proposta nesse Plano sob o paradigma da responsabilidade compartilhada - intersetorialidade ${ }^{3}$ - não cabendo apenas aos organismos específicos de políticas públicas para as mulheres promover a igualdade de gênero, mas a todos os órgãos, dos três níveis federativos, tanto horizontalmente (entre os ministérios), como verticalmente (níveis estadual, distrital e municipal). Cabe à Secretaria de Políticas para as Mulheres $\left(\mathrm{SPM}^{4}\right)$ a coordenação horizontal, devendo articular com os demais órgãos, organizar os trabalhos desenvolvidos, acompanhar e avaliar os resultados. 
Nesse paradigma, identificamos que o III PNPM é fruto do trabalho da SPM, dos membros de Comitê de Monitoramento e Articulação do PNPM, das conselheiras do Conselho Nacional dos Direitos da Mulher (CNDM), de diversos Ministérios e Secretarias 5 , bem como do resultado das Conferências de Mulheres a nível municipal, estadual e nacional (BRASIL, 2013).

Além de operar como princípio orientador de todas as políticas públicas, estando presente em ações de diferentes órgãos, verificamos que a transversalidade das políticas de gênero também se apresenta sob o paradigma da interseccionalidade, ou seja, as ações propostas atravessam diferentes áreas - trabalho, educação, saúde, segurança, cultura, direitos - bem como dirigem-se às múltiplas mulheres, em suas diferenças e desigualdades - mulheres de diferentes classes econômicas e níveis de escolaridade, mulheres urbanas e rurais, mulheres jovens, idosas, mulheres com deficiência, mulheres de diferentes etnias e orientação sexual - como observamos nos dez capítulos propostos pelo Plano: 1) Igualdade no mundo do trabalho e autonomia econômica; 2) Educação para igualdade e cidadania; 3) Saúde integral das mulheres, direitos sexuais e direitos reprodutivos; 4) Enfrentamento de todas as formas de violência contra as mulheres; 5) Fortalecimento e participação das mulheres nos espaços de poder e decisão; 6) Desenvolvimento sustentável com igualdade econômica e social; 7) Direito à terra com igualdade para as mulheres do campo e da floresta; 8) Cultura, esporte, comunicação e mídia; 9) Enfrentamento do racismo, sexismo e lesbofobia; 10) Igualdade para as mulheres jovens, idosas e mulheres com deficiência (BRASIL, 2013).

Após evidenciar o que o III PNPM entende por transversalidade das políticas de gênero e as formas como se apresentam para enfrentar as desigualdades de gênero no Brasil, nas próximas seções voltamos nosso olhar especialmente ao Capítulo 1 , para compreender as ênfases, tensões e desafios que a implementação da transversalidade das políticas de gênero produz, enquanto construto teórico e prático.

\section{Autonomia econômica para as mulheres pobres}

Analisamos nesta seção como a transversalidade das políticas de gênero tem sido proposta no Capítulo 1 do III PNPM, intitulado Igualdade no mundo do trabalho e autonomia econômica. Em um movimento inicial de análise, verificamos que a interseccionalidade também aparece nesse Capítulo, cujo objetivo é:

Promover a igualdade no mundo do trabalho e a autonomia econômica das mulheres urbanas, do campo e da floresta, considerando as desigualdades entre mulheres e homens, as desigualdades de classe, raça e etnia, desenvolvendo ações específicas que contribuam para a eliminação da desigual divisão sexual do trabalho, com ênfase nas políticas de erradicação da pobreza e na valorização da participação das mulheres no desenvolvimento do país (BRASIL, 2013, p.14).

É possível perceber que a ênfase desse Capítulo está nas políticas de erradicação da pobreza, e que a transversalidade é proposta com a finalidade de atender diferentes grupos de mulheres a fim de inseri-las no mundo do trabalho público ${ }^{7}$, valorizar a sua participação no desenvolvimento econômico e modificar as relações de gênero existentes no país. Entretanto, mesmo com o objetivo de contemplar as 
diferentes mulheres, percebemos que as ações desse Capítulo são direcionadas às mulheres pobres $^{8}$, principalmente quando se trata da educação e do ingresso no mundo do trabalho público.

Talvez essa preocupação em priorizar as mulheres pobres seja uma das consequências do processo de polarização dos empregos femininos: de um lado, encontram-se as mulheres executivas exercendo profissões intelectuais superiores, com alto grau de reconhecimento e salários, tais como médicas, advogadas, juízas, jornalistas, arquitetas, professoras universitárias, pesquisadoras; enquanto que do outro, estão as mulheres que se mantêm em ocupações tradicionalmente femininas, consideradas pouco qualificadas, com baixa remuneração e pouco valorizadas socialmente, como auxiliares de enfermagem, cuidadoras (que atendem idosos, doentes, crianças), empregadas domésticas, cozinheiras, faxineiras (HIRATA, 2009).

Esse processo de polarização resulta na exacerbação das desigualdades sociais e dos antagonismos, constatada não apenas entre mulheres e homens, mas entre os diferentes tipos de mulheres. Dessa forma, entendemos que antes de atender às mulheres mais favorecidas economicamente, é necessário alcançar uma igualdade social, de oportunidades, de escolaridade, de rendimentos, com as quais as mulheres pobres não são beneficiadas.

Identificamos, ainda, que a transversalidade das políticas de gênero é entendida como um construto teórico:

Enquanto construto teórico orientador, a transversalidade das políticas de gênero consiste em ressignificar os conceitos-chave que possibilitam um entendimento mais amplo e adequado das estruturas e dinâmicas sociais que se mobilizam - na produção de desigualdades de gênero, raciais, geracionais, de classe, entre outras (BRASIL, 2013, p. 10).

Assim, verificamos que as políticas públicas para a erradicação da pobreza de mulheres, nesse Capítulo, destacam a autonomia, em especial a autonomia econômica, como conceito-chave, como princípio norteador, que possibilita pensar a transversalidade das políticas de gênero. Autonomia como garantia de que

[...] deve ser assegurado às mulheres o poder de decisão sobre suas vidas e seus corpos; devem ser asseguradas as condições de influenciar os acontecimentos em sua comunidade e em seu país e de romper com o legado histórico, com os ciclos e os espaços de dependência, exploração e subordinação que constrangem suas vidas nos planos pessoal, econômico, político e social (BRASIL, 2004, p. 32).

A autonomia pode ser pensada a partir de três pontos de vista: econômico, físico e político. A autonomia física das mulheres diz respeito às questões relacionadas com a sua integridade física e com o seu direito sexual e reprodutivo, como a escolha para o uso de métodos contraceptivos, a decisão de ter ou não filhos, qual o melhor período para tê-los, quando interromper uma gravidez. A autonomia política, por sua vez, refere-se à presença das mulheres em espaços de tomada de poder, como nos governos e parlamentos, que por meio de lutas alcançaram direito de $30 \%$ das legendas dos partidos brasileiros. 
Entretanto, é sobre a autonomia econômica das mulheres que o Capítulo 1 é significado de modo particular, entendida como a capacidade dessas mulheres "[...] de serem provedoras de seu próprio sustento, assim como das pessoas que delas dependem, e decidir qual é a melhor forma de fazê-lo. Nesse sentido, autonomia econômica é mais que autonomia financeira, já que também inclui o acesso à previdência e serviços públicos” (SOF, 2015, p. 45).

Destacamos que talvez Beauvoir, no final da década de 1940, seja precursora ao considerar autonomia e independência praticamente como sinônimas. Beauvoir vinculava a ideia de independência à existência de uma profissão, afirmando que todas as conquistas femininas - o voto e outras liberdades cívicas - permanecem abstratas se não são acompanhadas de uma autonomia econômica: "[...] foi pelo trabalho que a mulher cobriu, em grande parte, a distância que a separava do homem, só o trabalho pode assegurar-lhe uma liberdade concreta" (BEAUVOIR, 1980, p. 449).

Autonomia e independência estão presentes na segunda onda9 do feminismo, pressupondo que as mulheres devem se constituir pelo trabalho em cidadãs livres e iguais. As diferentes correntes não abandonam essa ideia de autonomia, que, segundo Humm (1995), sugere uma antítese à dependência: "uma pessoa é tanto mais autônoma quanto menos dependente for de outrem” (HUMM, 1995, p. 18).

Verifica-se que a autonomia atinge de forma diferente as múltiplas mulheres. Trataremos, aqui, de modo particular sobre como a autonomia econômica atinge as mulheres pobres. Isso porque as mulheres mais favorecidas economicamente, além de terem acesso mais facilitado à educação e à informação, ao constituírem-se pelo trabalho e ingressarem no mundo público, podem contar com uma vasta e acessível rede de apoio - trabalhadores/as domésticos/as, creches, escolas infantis - para ajudá-las nos cuidados com a casa e com os filhos. Para essas mulheres, o trabalho, na maioria das vezes, é libertador e sinônimo de independência e autonomia econômica, pois a decisão de ingressar no mundo do trabalho público envolve um projeto de realização pessoal, com a escolha de uma profissão e ingresso em cursos superiores, e não apenas uma necessidade financeira, sujeitando-se a trabalhos menos valorizados socialmente.

Situação diferente ocorre com as mulheres pobres, para quem o trabalho público é decorrente das precárias condições econômicas. O trabalho, nesse caso, é motivado pelas necessidades familiares e, muitas vezes, constitui-se na única fonte de renda da família, para a sobrevivência e sustento do lar, "não se configurando obrigatoriamente como um meio de afirmação individual para a mulher" (PACHECO, 2005, p. 22). Ou seja, o trabalho nessa situação é mais uma questão de subsistência do que um desejo de realização pessoal, embora, de certo modo, acabe por trazer uma relativa autonomia econômica para essas mulheres.

Segundo Sarti (1996, p. 2), a dificuldade de afirmação individual das mulheres pobres aparece, talvez, "[...] como uma incongruência em seu universo moral. Onde os elos de obrigações em relação aos seus familiares prevalece sobre os projetos individuais". A renda, fruto do trabalho fora de casa, por ser muito pequena, não garante, na maioria das vezes, a sobrevivência familiar, mantendo esse grupo de mulheres dependente de recursos de outras pessoas ou instituições para viver. 
De acordo com Leon (2003), o trabalho até então era tido como uma atividade meramente social, não como assunto econômico. Seguindo os pressupostos da autora, entendemos que o sentido de autonomia econômica é alargado no Capítulo 1, uma vez que aqui o trabalho para as mulheres, de modo particular para as pobres, se associa com a ideia de geração de renda. Nesse Capítulo, o trabalho apresenta-se como uma resposta à crise do emprego, capacitando as mulheres, tornando-as competitivas e produtoras de renda, de forma a adequarem-se ao modo de produção capitalista.

Nesse sentido, percebemos que a transversalidade das políticas de gênero é entendida nesse Capítulo enquanto um construto teórico, e trava um debate sobre a necessidade do trabalho das mulheres, sobretudo das pobres, buscando devolver sua autonomia e afirmar a sua contribuição econômica. Trata-se de um enfoque na condição social e econômica dessas mulheres, ou seja, refere-se ao contexto material que define a sua situação: acesso precário à educação e por consequência ao emprego e à renda.

\section{Da educacionalização do social para a economização do social}

O Capítulo 1 atribui grande importância para a educação de mulheres, como forma de desenvolver sua autonômica econômica e aliviar problemas sociais como fome, pobreza, miséria, desemprego, vulnerabilidade. Eis a educacionalização do social, como nomeia Lockmann (2013). A educação é considerada pelo governo como uma aposta para a formação profissional das mulheres, que se estrutura na direção de ser uma política para a geração de emprego e renda no Brasil.

Assim, a autonomia econômica é apresentada como um construto teórico norteador da transversalidade das políticas de gênero e sua implementação se desdobra em um construto prático, por meio de políticas, programas, cursos educacionais de capacitação oferecidos às mulheres pobres, como um desafio para que sejam incluídas no mundo do trabalho público, como produtoras de renda.

[...] enquanto conjunto de ações e de práticas, a transversalidade das políticas de gênero constitui uma nova estratégia para o desenvolvimento democrático como processo estruturado em função da inclusão sociopolítica das diferenças tanto no âmbito privado quanto no público; sendo também, e sobretudo, necessária nos espaços de relação de poder e de construção da cidadania (BRASIL, 2013, p.10).

No campo da intervenção prática, é possível identificar um amplo e diversificado conjunto de experiências de qualificação protagonizadas pelo governo em parceria com organismos estatais, como os Institutos Federais de Educação, Ciência e Tecnologia, conforme podemos observar nas metas e ações propostas por esse Capítulo. 
Quadro 1 - Metas do Capítulo 1

Atender 180 mil mulheres em cursos de profissionalização e elevação de escolaridade em processos e programas distintos e descentralizados (inclusive Mulheres $\mathrm{Mil}^{10}$ ).

Capacitar 100 mil mulheres até 2014 (Mulheres Mil).

Fonte: Brasil (2013).

Quadro 2 - Ações do Capítulo 1

Ampliar a oferta de cursos de profissionalização articulados com o aumento da escolaridade, especialmente para mulheres em situação de vulnerabilidade social (Mulheres Mil).

Fortalecer a participação das mulheres nos programas e iniciativas de capacitação profissional, voltados especialmente para o ensino técnico-profissionalizante (Pronatec ${ }^{11}$ e outros).

Fonte: Brasil (2013).

Os efeitos dos cursos de profissionalização propostos para as mulheres nesse Capítulo nos possibilitam pensar a partir do princípio de uma educacionalização do social (LOCKMANN, 2013) para uma dimensão que se associa a uma economização do social, a qual anuncia a promessa de uma relativa autonomia econômica por meio da educação profissional. Desse modo, a economização do social surge sob a forma de políticas públicas de inclusão produtiva voltadas para atender às mulheres pobres, que se encontram marginalizadas do mundo do trabalho público.

Observa-se que a ideia de economização do social caracteriza-se como uma lógica da produção capitalista, por meio de uma organização que busca superar a separação entre capital e trabalho e garantir que as mulheres tenham acesso à educação, bem como aos meios de produção, conheçam o processo e além de produzirem, gerenciem seu trabalho e usufruam dos resultados do mesmo.

Os empreendimentos de economização do social assumem o desafio de estimular a autonomia econômica das mulheres, já que se fundamentam na articulação do binômio capital-trabalho, na apropriação individual dos meios de produção e dos resultados da produção, na prática da autogestão e do empreendedorismo, na apreensão de todo o processo produtivo por todas as trabalhadoras, na valorização de cada mulher a produzir.

Assim, as políticas públicas de inclusão produtiva para as mulheres presentes nesse Capítulo destinam-se às mulheres pobres a fim de economizá-las, pois utilizam a educação como forma de capacitá-las para o mundo do trabalho público, aperfeiçoar seu capital humano, torná-las “empreendedoras de si”, responsáveis pelo seu sustento e, muitas vezes, pelo sustento de sua família, contribuindo com o desenvolvimento econômico do país. 
As estratégias de economização do social apresentam-se com o objetivo de fazer com que as mulheres aprendam a ser empresárias de si, empreendedoras ou, como destaca Gadelha (2009), um "indivíduo-micro-empresa". Ser um "indivíduomicro-empresa" significa ter uma visão empreendedora sobre sua própria vida, perceber as oportunidades, assumir os riscos e ser o responsável pelo seu sucesso ou fracasso. Trata-se da emergência da cultura da empresa ou do empreendedorismo mesmo para as mulheres pobres (GADELHA, 2009).

No caso do Capítulo 1, desenvolver estratégias para tornar as mulheres empreendedoras significa tornar a cultura do empreendedorismo uma forma de vida, criando subjetividades relacionadas. Refere-se não apenas a investimentos financeiros a serem aplicados em empresas e negócios, mas a investimentos que as mulheres pobres podem realizar nelas mesmas, em sua educacionalização, capacitação, aprendizagem, desenvolvimento, para atingir a sua economização.

Assim, o alcance da autonomia econômica e da igualdade de gênero perpassa o acesso à renda, depende dos processos de educação, da formação do capital humano, da cultura do empreendedorismo, da economização do social. Embora não seja a renda a única fonte de autonomia das mulheres, é importante destacar a autonomia econômica como forma de superar a divisão sexual do trabalho e a desigualdade existente entre as atividades realizadas por mulheres e homens - desigualdade de valor e de rendimentos - para o alcance da equidade de gênero.

Portanto, as ações voltadas à educação, ao trabalho e à geração de renda, propostas no Capítulo 1, têm demonstrado um campo privilegiado para exercitar a transversalidade das políticas de gênero, sob novas práticas e vivências de igualdade e de autonomia econômica para as mulheres pobres. Percebemos que as iniciativas de economização do social, manifestadas em forma de cursos profissionalizantes, representam um espaço portador de alternativas de politização das relações da vida, das relações de gênero, de empoderamento social e de construção da cidadania.

Contudo, a tensão encontrada nesta pesquisa talvez esteja ao considerar que essas mulheres tornam-se empreendedoras após a participação em programas como o Pronatec e o Mulheres Mil, visto que se tratam de cursos de curta duração, que acabam por reforçar as atividades ditas femininas, tais como cozinheira, bordadeira, costureira, artesã. Dessa forma, questionamos se os investimentos educacionais por parte do Estado brasileiro são suficientes para tornar as mulheres empreendedoras e de fato economizá-las ou se são políticas compensatórias, focalizadas nas mulheres, conforme sugere Bandeira (2004). Segundo essa autora, enquanto as políticas focadas nas relações de gênero buscam compreender a diferenciação entre os processos de socialização do feminino e do masculino, bem como dar visibilidade aos mecanismos culturais que envolvem as formas de subjetivação e diferenciação entre mulheres e homens, as políticas focadas nas mulheres, como esse Plano, são alicerçadas por pressupostos essencialistas e reforçam os processos que envolvem a reprodução e a sexualidade como inerentes às mulheres, justificando, assim, a necessidade e a criação de políticas compensatórias para as assimetrias de gênero daí decorrentes. $O$ resultado são políticas que reforçam o fato de que a pobreza é maior entre elas, oferecendo cur- 
sos de capacitação para atividades consideradas extensões das já realizadas dentro de casa e sem reconhecimento social.

Assim, os cursos de capacitação empreendedora para a economização do social têm sido o grande desafio das políticas de inclusão produtiva para as mulheres e se desenham sobre o pressuposto da inserção no mundo do trabalho público e da conquista da autonomia econômica, como forma para superar as condições de pobreza em que se encontram. Segundo Bandeira $(2004$, p. 9) “[...] em longo prazo, as políticas para as mulheres devem se transformar em políticas de gênero". Essas políticas colocam em pauta nas agendas públicas ações que caminham no sentido de operar com a transversalidade e alcançar, de fato, a igualdade de gênero.

\section{Algumas considerações}

Mesmo com o aumento da participação das mulheres no mundo do trabalho público nas últimas décadas, conduzindo, pelo menos em parte, a uma maior autonomia das mulheres, muito pouco dos seus papéis de mãe e esposa foram alterados, principalmente quando se trata de mulheres pobres. Além disso, os efeitos da crescente participação das mulheres não foram acompanhados de uma diminuição significativa das desigualdades profissionais de gênero, cabendo a elas empregos informais, precários e mal remunerados. É nessa "[...] inserção carreira-família que vão se configurar os grandes impasses enfrentados pela mulher em seu percurso singular de atuação que, por si só, [...], já a situam distante da pretensa 'igualdade"' (ROCHACOUTINHO, 2000, p.80-81).

São poucas as mulheres brasileiras que conseguem, somente com sua ren$\mathrm{da}$, alcançar uma autonomia financeira. A maior parte, devido à condição de pobreza, trabalha fora de casa muito mais por uma questão de sobrevivência. Sendo assim, o Estado cria políticas de inclusão produtiva para as mulheres, com atenção especial para as pobres, com o intuito de capacitá-las para o mundo do trabalho público, aumentar a geração de renda e, consequentemente, suas autonomias. Todos devem participar do jogo do mercado econômico. Para aqueles que não têm condições de iniciar o jogo, o Estado deve prover recursos mínimos que garantam pelo menos a sua entrada, recursos esses proporcionados ao longo das metas e ações que compõem o Capítulo aqui analisado.

Tais ações enfatizam a educação, na forma de cursos de capacitação, como forma de promover a transversalidade das políticas de gênero, a autonomia econômica e a igualdade de gênero. Contudo, percebemos que os efeitos da implementação desses cursos geram uma tensão, pois atingem, em parte, o objetivo proposto, com a inclusão produtiva de mulheres, atendendo às exigências do capitalismo, mas acabam por reproduzir atividades domésticas, rotineiras, pouco remuneradas e que não fazem uso de tecnologias avançadas.

As atividades domésticas e o cuidado com os filhos permanecem sendo de responsabilidade das mulheres, e a sua inserção no trabalho público é tida como um complemento da atividade principal e mantenedora do lar: o trabalho dos homens. 
As mulheres, ainda hoje, sofrem com a acumulação da dupla jornada e com a divisão sexual do trabalho, que é reforçada pelos cursos de capacitação profissional propostos no Capítulo 1. Há uma subestimação da importância do trabalho doméstico e reprodutivo realizado pelas mulheres, negando sua posição econômica, considerada como secundária e sem valor econômico.

Verificamos que a autonomia econômica gerada pelas ações presentes em tal Capítulo corresponde a uma autonomia imaginária e não real, visto que a renda obtida por meio dos cursos de profissionalização não é gasta individualmente pelas mulheres. A renda é transferida para a família, para o bem-estar e qualidade de vida. Entendemos que se trata de uma autonomia imaginária e não real, pois a geração de renda pelo trabalho implicaria no aumento da liberdade de gastá-la, o que não ocorre.

O desafio é agirmos na contramão dos cursos de educação profissional focados nas mulheres, ou seja, tentarmos vislumbrar novos caminhos que alterem as configurações de gênero vigentes. Consideramos necessária a ampliação da educação para além da construção de uma política de governo para treinamento e adestramento profissional para a aquisição de capital. Para alcançar, de fato, a autonomia econômica, é necessário investir na educação numa perspectiva de formação integradora e integrada de caráter politécnico, de forma continuada, desde os primeiros níveis, e incentivar a verticalização do ensino, com o ingresso em cursos como EJA ${ }^{12}$, cursos técnicos e até mesmo superiores. Educação essa que contribua para forjar um projeto de formação humana e que não se configure somente para o trabalho e geração de renda, mas que dê oportunidades para a atuação técnica, política, ética e competente das mulheres.

Destacamos, assim, a ênfase desse Capítulo na proposta para a implementação de políticas para a erradicação da pobreza e valorização das mulheres no desenvolvimento econômico do país. A transversalidade de gênero atravessa essas políticas por meio do pressuposto da autonomia econômica, voltada às mulheres pobres e excluídas socialmente, na tentativa de, em um primeiro momento, alcançar a igualdade entre diferentes grupos de mulheres, para depois buscar a igualdade entre mulheres e homens. O grande desafio desse Capítulo está em utilizar a educação como lócus privilegiado para capacitar as mulheres em situação de vulnerabilidade social para o mundo do trabalho público e empreendedor, juntamente com a formação humana. Eis a educação como princípio impulsionador da economização do social.

\section{Referências}

BANDEIRA, L. A transversalidade da perspectiva de gênero nas políticas públicas. Brasília, DF: Comissão Econômica para América Latina e Caribe - CEPAL; Secretaria Especial de Política para as Mulheres - SPM, 2004. Disponível em: <http://www.spm.gov.br/arquivos-diversos/.arquivos/integra_transversalidade_genero >. Acesso em: 02 jul. 2016.

BEAUVOIR, S de. O segundo sexo. Rio de Janeiro, Nova Fronteira, 1980 [1949].

BRASIL. Presidência da República. Secretaria de Políticas para as Mulheres. Plano Nacional de Políticas para as Mulheres. Brasília: Secretaria Especial de Políticas para as Mulheres, 2004. 104 p. Disponível em <http://www.spm.gov.br/assuntos/pnpm/plano-nacional-politicas-mulheres.pdf>. Acesso em: 15 abr. 2016. 
BRASIL. Presidência da República. Secretaria de Política para as Mulheres. Plano Nacional de Políticas para as Mulheres. Brasília: Secretaria de Política para as Mulheres, 2013. Disponível em: <http://www.spm.gov.br/assuntos/pnpm/publicacoes/pnpm-2013-2015-em-22ago13. pdf $>$. Acesso em: 25 Ago. 2015

BRASIL. Pronatec. Brasília: Ministério da Educação, 2016. Disponível em: <http://portal.mec. gov.br/pronatec>. Acesso em: 23 dez. 2016.

CANTERLE, N. M. G. A reorganização do trabalho no mundo do trabalho. De Gerencia Gerencia y Negociosen Hispano América, 2003. Disponível em: <http://www.degerencia.com/ articulo/a_reorganizacao_do_trabalho_no_mundo_do_trabalho>. Acesso em: 14 abr. 2016.

CELLARD, A. A análise documental. In: POUPART, J. et al. A pesquisa qualitativa: enfoques epistemológicos e metodológicos. Petrópolis: Vozes, 2008.

CHANTER, T. Gênero: conceitos-chave em filosofia. Porto Alegre: Artmed, 2011.

GADELHA, S. Biopolítica, governamentalidade e educação: introdução e conexões, a partir de Foucault. Belo Horizonte: Autêntica Editora, 2009.

GONÇALVES, E. Vidas no singular: noções sobre "mulheres sós” no Brasil contemporâneo. 2007. 275 f. Tese (Doutorado em Ciências Sociais) - Instituto de Filosofia e Ciências Humanas, Universidade Estadual de Campinas, Campinas, 2007.

HEILBORN, M. L.; ARAÚJO, L.; BARRETO, A. (Orgs.). Gestão de políticas públicas em gênero e raça / GPP - GeR: módulo V. Rio de Janeiro: CEPESC; Brasília: Secretaria de Políticas para as Mulheres, 2011.

HIRATA, H. A Precarização e a Divisão Internacional e Sexual do Trabalho. Sociologias, Porto Alegre, ano 11, n. 21, p. 24-41, jan./jun. 2009.

HUMM, Magie. The dictionary of feminist theory. Ohio State: University Press, 1995.

IBGE - INSTITUTO BRASILEIRO DE GEOGRAFIA E ESTATÍSTICA. Censo, 2010. Disponível em: <http://www.censo2010.ibge.gov.br/>. Acesso em: 23 jul. 2014.

JOHNSON, R. O que é, afinal, Estudos Culturais? In: SILVA, T. T. da. (Org.). O que é, afinal, Estudos Culturais. Belo Horizonte: Autêntica 2006.

LEON, M. Pleno empleo y el trabajo de las mujeres. In: FARIA, N. (Comp). Construir la igualdad. São Paulo: REMTE - Red Latino Americana Mujeres Transformando la Economia, 2003. p. 19-28.

LOCKMANN, K. A Proliferação das Políticas de Assistência Social na educação escolarizada: estratégias da governamentalidade neoliberal. 2013. Tese (Doutorado em Educação) - Programa de Pós-Graduação em Educação, Faculdade de Educação, Universidade Federal do Rio Grande do Sul, Porto Alegre, 2013.

LOURO, G. L. Currículo, gênero e sexualidade: o "normal", o "diferente" e o "excêntrico". In: LOURO, G. L.; FELIPE, J.; GOELLNER, S. V. Corpo, gênero e sexualidade: um debate contemporâneo na educação. Petrópolis: Vozes, 2003. p. 41-52.

MATTELART, A.; NEVEU, É. Introdução aos estudos culturais. São Paulo: Parábola Editorial, 2004.

MEYER, D. E. Abordagens pós-estruturalistas de pesquisa na interface educação, saúde e gênero: perspectiva metodológica. In: MEYER, D. E.; PARAÍSO, M. A. (Org.). Metodologias de pesquisas pós-críticas em Educação. Belo Horizonte: Mazza Edições, 2012.v. 1, p. 47-62.

MEYER, D. E. Gênero e educação: teoria e política. In: LOURO, G. L.; NECKEL, J. F.; GOELLNER, S. V. (Orgs.). Corpo, gênero e sexualidade: um debate contemporâneo na Educação. Petrópolis, RJ: Vozes, 2003. p. 9-27. 
NICHOLSON, L. Interpretando o gênero. In: Estudos Feministas. Florianópolis: UFSC, 2000. v. 8, n. 2, p. 9-41.

PACHECO, A. L. P. de B. Mulheres pobres e chefes de família. 2005. 253 f. Tese (Doutorado em Psicossociologia de Comunidades e Ecologia Social) - Universidade Federal do Rio de Janeiro - Instituto de Psicologia, 2005.

ROCHA-COUTINHO, M. L. Dos contos de fada aos super-heróis: mulheres e homens brasileiros reconfiguram identidades. Psicologia Clínica, Rio de Janeiro: PUC/Departamento de Psicologia, 2000, 12, (2), 65-82.

SARTI, C.A. Família e individualidade: um problema moderno. In: CARVALHO, M. do C. B. A família contemporânea em debate. São Paulo: EDUC/Cortez Editora, 1996. p. 39-49. (Série Eventos).

SOF - SEMPREVIVA ORGANIZAÇÃO FEMININA. Feminismo em marcha para mudar o mundo: trajetórias, alternativas e práticas das mulheres em movimento. São Paulo, 2015. Disponível em: <http://www.sof.org.br/wp-content/uploads/2015/09/Caderno-de-textos-web. pdf>. Acesso em: 17 abr. 2016.

VIOTTI, M. L. R. Declaração e plataforma de ação da IV Conferência mundial sobre a mulher - Pequim 1995. In: FROSSARD, H. (Org.). Instrumentos Internacionais de Direitos das Mulheres. Brasília: Secretaria Especial de Políticas para as Mulheres, 2006. 260p. (Série Documentos). Disponível em: <http://www.compromissoeatitude.org.br/wpcontent/uploads/2012/08/SPM_instrumentosinternacionaisdireitosdasmulheres.pdf $>$. Acesso em: 28 de mar. 2015.

\section{Notas}

${ }^{1}$ A pesquisa proposta teve início em março de 2014 e será concluída em março de 2018. Pretende dar sequência a uma agenda de investigação que vem problematizando as interfaces entre gênero e políticas de inclusão social no Brasil, na perspectiva dos Estudos de Gênero e Culturais pós-estruturalistas. Para avançar na discussão, a pesquisa analisa os documentos normativos das políticas e programas Saúde na Escola, III PNPM, Gênero e Diversidade na Escola, Rede Cegonha, Atenção Integral à Saúde das Mulheres, Atenção Integral à Saúde dos Homens, bem como publicações e pesquisas que tematizam a transversalidade de gênero. Os materiais estão sendo analisados na perspectiva da análise cultural ancorada na teorização foucaultiana, para responder a três questões: 1) como - do ponto de vista das ênfases, tensões e desafios - a proposição governamental da transversalidade de gênero tem sido apresentada e proposta nos textos programáticos das políticas de inclusão social que temos analisado no grupo?; 2) quais tem sido as ênfases, tensões e desafios apontados por estudos que têm discutido e analisado essa proposição de transversalidade de gênero em políticas públicas (no Brasil e fora dele) na confluência das áreas da educação e da saúde, e como tem se posicionado diante de tais questões?; 3) como as pesquisas que temos realizado, em nosso grupo de pesquisa, dialogam com essa produção? Por se tratar de uma pesquisa ainda em andamento, os resultados ainda estão em processo de produção.

${ }^{2}$ O III PNPM é resultado da 3a Conferência Nacional de Políticas para as Mulheres (CNPM), realizada em 2011, e constitui-se em um documento composto por 114 páginas. Dessas, somente seis referem-se ao Capítulo 1, objeto de análise desta pesquisa. Da mesma forma, o I e II PNPM são frutos da 1a e 2a CNPM, ocorridas em 2004 e 2007, respectivamente (BRASIL, 2013). Em 2016 ocorreu a 4a CNPM, contudo, ainda não foi lançado o IV PNPM.

${ }^{3}$ De acordo com Heilborn, Araújo e Barreto (2011, p. 37), a intersetorialidade "consiste na promoção de ações integradas entre os diferentes órgãos setoriais [...] permitindo melhor utilização de conhecimentos e experiências acumuladas, colaborando para o alcance de metas comuns, sob uma coordenação que agrega todas as contribuições". 
${ }^{4}$ A medida provisória (MPV) de 02 de outubro de 2015 extingue o cargo de Ministro de Estado Chefe da Secretaria de Políticas para as Mulheres, vinculando essa secretaria ao Ministério das Mulheres, da Igualdade Racial e dos Direitos Humanos. Em 2016, tal secretaria passa a integrar o Ministério da Justiça e Cidadania.

${ }^{5}$ Ministério da Educação (MEC), Ministério do Desenvolvimento Social (MDS), Secretaria de Políticas para as Mulheres (SPM), Secretaria de Relações Internacionais (SRI), Ministério do Trabalho e Emprego (MTE), Secretaria Nacional de Juventude da Secretaria Geral da Presidência da República (SNJ/SG/ PR), Ministério das Relações Exteriores (MRE), Secretaria de Políticas de Promoção da Igualdade Racial (Seppir), Ministério de Desenvolvimento Agrário (MDA), Secretaria dos Direitos Humanos (SDH), Secretaria de Comunicação Social (Secom), Ministério do Turismo (MTur), Ministério da Previdência Social (MPS), Ministério da Fazenda (MF) (BRASIL, 2013).

${ }^{6} \mathrm{~A}$ interseccionalidade considera a existência de eixos de subordinação, que geram situações de desigualdade e discriminação, como o racismo, o patriarcalismo, a opressão de classe (HEILBORN, ARAÚJO e BARRETO, 2011).

${ }^{7}$ Utilizamos o termo mundo do trabalho, ao invés de mercado de trabalho, pois "[...] o conceito de mundo do trabalho é mais amplo que a função laboral no sentido estrito. Incluem-se nele tanto as atividades materiais, produtivas, como os processos sociais que the dão forma e sentido no tempo e no espaço" (CANTERLE, 2003, n.p.). Utilizamos, ainda, mundo do trabalho público, conforme empregado pelas feministas em oposição ao trabalho privado, doméstico e familiar. O trabalho no espaço privado "[...] tem figurado como confinador e restritivo, um espaço de que as mulheres devem migrar a fim de se libertarem para realizar as liberdades que os homens assumem no espaço público. Esse espaço público tem figurado como um espaço de liberdade e de libertação, caracterizado pela oportunidade de trabalho e de educação, e pela proteção da lei" (CHANTER, 2011, p. 28). Conforme a autora, o trabalho privado é marcado pelo feminino, enquanto que o trabalho público, pelo masculino.

${ }^{8}$ No Brasil, são considerados vulneráveis à pobreza os indivíduos com renda domiciliar per capita igual ou inferior à metade $(1 / 2)$ do salário mínimo. São definidos como pobres os indivíduos com renda familiar per capita igual ou inferior a um quarto (1/4) do salário mínimo. E são considerados indivíduos extremamente pobres aqueles cuja renda per capita mensal é igual ou inferior a $\mathrm{R} \$ 70,00$ (setenta reais) mensais (IBGE, 2010).

9 "Não podemos desconsiderar, no entanto, a contribuição das pioneiras do século XIX e das feministas que perseveraram nos anos 1920 na luta por igualdade em contextos políticos menos favoráveis” (GONÇALVES, 2007, p. 146). Assim, destacamos a importância da primeira onda feminista e sua relação com o trabalho.

${ }^{10}$ O Programa Mulheres Mil é uma das ações do MDS, inserido no Plano Brasil Sem Miséria (BSM), no eixo da inclusão produtiva urbana. Associa qualificação profissional e tecnológica com promoção e elevação da escolaridade para mulheres em situação de vulnerabilidade social. Em 2014 passou a integrar o Programa Nacional de Acesso ao Ensino Técnico e Emprego (Pronatec).

${ }^{11}$ O Pronatec foi criado pelo governo federal em 2011, com o objetivo de expandir, interiorizar e democratizar a oferta de cursos de educação profissional e tecnológica no país. O Pronatec busca ampliar as oportunidades educacionais e de formação profissional qualificada aos/às jovens, trabalhadores/as e beneficiários/ as de programas de transferência de renda, articulando política e educação profissional e tecnológica, para a geração de trabalho, emprego e renda (BRASIL, 2016).

${ }^{12}$ Educação de Jovens e Adultos, para pessoas que não concluíram o ensino fundamental e/ou médio na idade apropriada. 
III plano nacional de políticas para as mulheres: a transversalidade de gênero e a educação

* Professora do Instituto Federal Farroupilha, São Borja, Rio Grande do Sul. Brasil.

** Professora da Universidade Regional do Noroeste do Estado do Rio Grande do Sul, Ijuí, Rio Grande do Sul. Brasil.

\section{Correspondência}

Fernanda de Magalhães Trindade - Instituto Federal Farroupilha, Campus São Borja. Rua Otaviano Castilho Mendes, 355. CEP: 97670-000. São Borja, Rio Grande do Sul, Brasil.

E-mail: fernanda.trindade@iffarroupilha.edu.br - simone@unijui.edu.br

Recebido em 24 de agosto de 2016

Aprovado em 13 de janeiro de 2017 
